\section{EAHP news for January issue}

\author{
Richard Price
}

\section{PATIENTS SUFFERING FROM MEDICINE SHORTAGES IN ALL EUROPEAN COUNTRIES}

A new report on medicine shortages experienced in European healthcare systems reveals that over $86 \%$ of hospital pharmacists are experiencing difficulties in sourcing medicines with $66 \%$ reporting this as a daily or weekly problem. The top-affected areas are medicines to fight infection, cancer drugs and anaesthetics.

The report by the European Association of Hospital Pharmacists (EAHP) surveyed the experiences of over 600 hospital pharmacists in 36 European countries and presented a striking picture of how medicine shortages are affecting the treatment of patients across the continent.

A total of $75 \%$ of surveyed hospital pharmacists either agreed or strongly agreed with the statement 'medicines shortages in my hospital are having a negative impact on patient care'. Consequences for patients included delayed or interrupted chemotherapy treatment, unnecessary experience by patients of side effects, heightened Clostridium difficile risk and deterioration in patients' conditions.

In addition to this, hospital pharmacists reported the enormous costs in time diverted to sourcing alternative supplies, increased stress and confusion within safety critical working environments, the frequent high costs of procuring alternative medicines than those prescribed and the cancellation of service improvements due to resources needing to be reallocated to deal with medicines shortages.

Correspondence to Richard Price, Department of Policy and Advocacy, European Association of Hospital Pharmacy, 3 Rue Abbe Cuypers, Brussels 1040, Belgium; richard.price@eahp.eu
Launching the report at the Brussels Press Club, EAHP President Dr Roberto Frontini said:

Two things always shock me about the medicines shortages problem in Europe: its scale, and the known impacts it is having on patient safety and welfare.

For too long this problem has been brushed under the carpet. It is time for those with responsibility for protecting European citizens from cross-border health threats to address the issue.

We need improved systems for ensuring early reporting of medicines supply disruptions, with causes, likely duration and available alternatives notified to healthcare professionals. We need a step change in the recording of information about the problem. This could be addressed by the European Medicines Agency developing a database of medicines in shortage across Europe replicating that of its counterpart in the USA. We need criteria for a fair distribution in case of shortages based on patient's needs and not on commercial interests. Finally, we need an urgent sense of responsibility to be adopted by the European Commission in leading both investigation and resolution of the problem.

As our report makes clear: medicines shortages are a cross border health threat to patient welfare and the time for EU action is now.

\section{PROFESSOR DR KEES NEEF HONOURED WITH LIFETIME ACHIEVEMENT AWARD}

EAHP is delighted to share the news that Professor Dr Kees Neef, EAHP Director of Education, Science and Research, has been honoured in his home country of the Netherlands with the prestigious Jan Glerum Lifetime Achievement Award.
The award was presented at the end of a recent two-day Dutch hospital pharmacy conference in Rotterdam, attended by over 300 Dutch pharmacists. The award was made in recognition of the work Kees has conducted throughout his professional life towards the training of hospital pharmacists.

In making the award, the prize jury was particularly struck by the great value of the training Professor Neef has given to pharmacists in the use of pharmacokinetic software packages, which has enabled their subsequent uptake and use in nearly all Dutch hospital pharmacies. This development in itself has provided the foundation for a step change in research activity in the Netherlands and supported the evolution of clinical pharmacology services.

Commenting on the award, Dr Roberto Frontini, President of the EAHP, said:

I can think of few other hospital pharmacists more deserving of a lifetime achievement award than Prof. Dr. Kees Neef. It is an honour to work with him on the EAHP Board and to have him leading our busy Scientific Committee. For Kees, there's no such thing as 'good enough', and we gain immensely from this drive for improvement in his stewardship of our education activities.

The Netherlands and Maastricht are fortunate to benefit from the contributions of such a passionate and committed member of the hospital pharmacy profession. I, and EAHP, also count ourselves privileged to continue to profit from his infectious enthusiasm. The prize jury has chosen wisely!

Competing interests None.

Provenance and peer review Commissioned; internally peer reviewed.

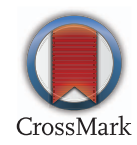

To cite Price R. Eur J Hosp Pharm 2015;22:61. Accepted 24 November 2014

Eur J Hosp Pharm 2015;22:61. doi:10.1136/ejhpharm-2014-000597 